\title{
Reflecting from the fringe: on expanding the analytic frame \\ Assie Gildenhuys
}

Establishing group analytic psychotherapy as part of the academic offering in a clinical psychology training program requires revisiting the models and basic stance to training. The paper outlines the significant shifts adopted changing a traditional lecturer-centred approach to a relational model. Some of the arresting dilemmas created by social and academic isolation are highlighted. The significance of a personal validating participatory experience in bridging the divides is then discussed. The important role of Malcolm Pines in liaising, encouraging links and forging theoretical refinement and expansion is reviewed. Lastly the affirming contribution of scholarly works and the professional discourse in widening the group analytic practice is indicated.

Key words: group work, internationalisation, group analysis, median group, social transformation, transcultural exchange

\section{Introduction}

Group-analysis is a form of Psychotherapy in small Groups and also a Method of studying Groups and the behaviour of Human Individuals in their social aspects (Foulkes, 1948, p. vii). (capital letters in the original)

In this article I share distinct phases in the development of a workable frame of group analytic thinking. I try to a capture some distinct aspects of this development which will be discussed under the following headings: a conventional response to teaching demands, forging a relational teaching foundation and the transcultural setting.

The main emphasis will be on how the demands of the situation and the accessible material paved the way to formulate a view on group work and training. Group therapy training at most university departments in the South African remains non-aligned (there is no formal group psychotherapy representative body) and based on general group work principles. Group therapy forms part of the curriculum but is secondary to the core individual psychotherapy models. 
The conceptual inquiry has had a wide basis therefore acknowledges the contribution from various fields and journals other than Group Analysis but will focus on the group analytic literature. I situate the review and conclusions within the historical setting and contemporary developments.

Referring now to the phases mentioned. The first happened during the social and academic isolation of the early 80's and ends in my first personal experience in the international arena in 1992. The second refers to a sabbatical spend in the London (1994-1995) and the third the period of reconnecting and present positions (1996-). The time frame outlined makes it possible to illustrate two simultaneously occurring dynamics namely:

- teaching demands directs the process of formalization (acceptable practices) and;

- group-analytic analysis of tension within training relations ushers in a reflective practice.

\section{A conventional response to teaching demands}

My interest in the field of group therapy was based on my experience in an experiential encounter group during my training as clinical psychologist (1978). This lead to my interest in experiential learning in an academic program. Formulating a conceptual framework directed the academic review of available published literature of that era (80's). This period was characterised by academic isolation leaving a profound inner sense of being an outsider. It made me appreciation the feeling of being disenfranchised and how difficult it can become to regain a sense of connectedness and interest in other - defensive alienation. The literature revealed various stances to group work. This was the period of assimilation and differentiation and defining a working model. Although diversity and approaches were acknowledged my conceptualisation of the therapeutic group remained diffuse affecting the training setting.

Fortunately I had access to an up to date subscription of the Group Analysis journal (1967-), the International Journal of Group Psychotherapy (1951-) and the journal Small Group Research. The available textbooks (Shaffer \& Galinsky, 1974; Kaplan \& Sadock, 1983; Yalom, 1985; Agazarian \& Peters, 1981; Durkin, 1964; Wolberg, 1982) documented the scope of the therapeutic traditions.

I identified the following clusters relevant to group work and forming the basis of a conceptual working model:

- emphasis on the structuring of the small group encounter;

- the immediacy of the interpersonal connection

- the value of interpersonal learning;

- working in the here and now;

- conceptualising the group-as-a-whole

- the process of group development 
- capacity and skillfulness of the therapist/conductor;

- guiding principles around member selection and preparation, management, goal formulation, and duration

- socio-cultural change and development and the effect of macro social transition;

- professional identity and development;

- research - refinement, adaptation , assimilation and development of constructs and the scope of practice.

These provided much insight in establishing an internationally verified training frame and basis for structuring the body of available knowledge. During this period it provided affirmation to establishing local training and forged a professional alliance.

Responding to the required traditional teaching model that relies heavily on structuring (constructs) and application (skills) lead to a formal format of representation. At the time the group therapy training was accommodated in the clinical training as a secondary tier but with limited appreciation. With limited group level exchange in the faculty marginalisation was also carried over into the training group. I suspect that the group course also had to carry much of the tensions in the wider group. In short the social isolation carried over into the academic setting and partially became located in the group program.

Interestingly this was also the period in which our small training team (2) was occupied with power and authority and tended to respond primarily to transferential and group-as-a-whole manifestations in the trainee groups. This lead to a what seemed irreconcilable tensions and challenged the training format and content.

\section{Forging a relational teaching foundation}

During the period (1992-1995) personal contact and exposure to the international group work arena happened. This involved participation in the first international group therapy conference and various training experiences (1992).During a sabbatical in London(199495), participation in a therapy group, introductory course, workshops, seminars and scientific meetings affirmed my inclination to group analytic thinking. These exposures allowed me a personal and group space where I could rethink my relation to my work setting as well as the effect of my cultural heritage. Not only was I introduced to group analysis but also divers settings. The use of small and large group challenged and broadened my views. It was predominantly the large group environment that became more prominent because this was an area of learning and thinking that I had never previously encountered. Taking the larger social structures e.g. institutions and organisations or the transcultural group (participating in the workshop in Paris 1995) expanded the relational frame even further.

On my return I was confronted with some fundamental changes in the department structure and management. Adding to this I experienced an inability to translate my learning into 
communicable ideas. This lead to a different era of distancing and some social isolation. Gradually I re-entered the group analytic thinking and transform my understanding to become accessible to my planning on the post graduate courses. It came about through accommodating and reflecting on the various relations. This would certainly merit another discussion but making relations central in academic training has made the groups come alive. Emotional tensions like defensiveness, fears, uncertainties and reservations become shareable and workable.

Although the benefits of this reformulation might seem obvious, registering the mental group representations pave the way for this development. The experiential connection to significant group experiences paired with the continuous scientific deliberation sustains this position.

This has also permitted me to connect with personal group level tensions that are part of my cultural grouping and to struggle with the alienation which become apparent in public representations.

The distinct change in my mental stance, compared to the delineation above, can be summarised in the following focus areas:

- defining the frame in the setting;

- maintain the analytic attitude and select constructs that facilitate frontier exchange in an inter-disciplinary environment;

- construct a holding conceptual frame that decentralised (the individual psychological perspective influence) and centralises (the communicational and relational network);

- convey fundamental constructs to map out the conceptual domain;

- select relevant and readable sources from various perspectives - facilitative to diversity and development.

\section{The transcultural setting:}

I now turn to the third and at present most dynamic part of my interests. By becoming involved in various institution-wide group projects I had to broadening the group analytic base. In this work the social matrix in the health setting and training groups in informal structures has become the focus. Working not only in a transcultural setting but against the backdrop of socio-economical and social disadvantaged communities, demands dedicated social and group analytic formulations. Rapid and accelerated social transitions and continuous transformations create insecurities and suspicion. Cultural diversity and historical divides creating a tremendous pressure on staying civilised with occasional strong group level acting out e.g. boundary disasters (Parker, 1996).. Such work can not be undertaken without the support of a training faculty that can help process and maintain various links in the setting.

The following areas can be useful in providing some coherence in the face of such colossal forces encountered in median and large groups: 
- explore the culturally familiar, divers and alien;

- imbedded social heritage and forced divides -encountering the often displaced apprehension;

- observable regulation of social order and challenging the lack of exchange;

- residual tension about the 'other' in the situation as totality;

- Convening, management and maintenance in the transcultural field - a shared endeavour;

- Response to the compounding effect - how to maintain a receptive attitude.

I suggest each of these stages and transitions requires a mental attunenss and engagement. I now want to focus on how group analysis and Malcolm Pines' work has contributed to my present understanding. It has lead to a reflective practice to teaching and greater endorsement of the indigenous nature of the social self.

\section{Pines' contribution to group-analytic theory}

Leading from the previous discussion (especially during phase 2) the relevance in entertaining some constructs offered by Pines will become apparent. It is not intended as a critical analysis or comprehensive review but demonstrates the development of becoming more attuned to the complex relational demands within my professional work. Establishing group analysis as a credible and transferable frame amongst competitive academic paradigms demands rigorous comparative analysis. Tapping into sources that conveyed the historical and contemporary links to other established fields provide an accountable and sustainable check.

\section{Establishing the frame of group analysis}

Foulkes' position of 'non-alignment' (1976) (1964c) (1982) is liberating. Although acknowledging reliance on psychoanalytic thinking and practice he also reminded us how important it is to develop constructs that would describe group specific phenomena. Much of contemporary debate (Nitsun, 1996; Dalal, 1998; Nitzgen, 2008) reengages with this and highlights the unique pioneering tensions he assimilated and responded to.

Consulting his writing did provide an appreciation of an open system that fosters a gradual development of a working frame. To my understanding Foulkes deliberately canvassed for a middle position; a position that would be tolerable within some established intellectual cultures in England and Europe but also in America (from the editorial comments in the first publication (1967). He wanted to maintain the non-aligned mental space to create the potential for group analytic understanding. He was thus promoting both a stance of inquiry and a state of engagement not only with the group members but also (Foulkes, 1975b) the society in transition.

The assimilation of new scientific terminology capturing the Foulksian view requires rereading the original sources. The unfolding progress of deciphering, refinement and 
clarification is a continuous endeavour of the group analytic community. Making these available for broader assimilation and inviting wider application has stimulated interesting work and challenge new frontiers.

In this regard I found Pines’ work informative. I am specifically referring to the group analytic frame and 'three bodied' psychology. By using a comparison between the more 'familiar' and established understanding of psychoanalysis he demarcates, illuminates and identifies the frame of group analysis (Pines, 1978a; Pines, 1981). In the first paper he described the significant shifts when Freud isolated the patient from the social frame and created the therapeutic frame. He identified other theoretical shifts that paved the ways to work with the group as frame and the acknowledgement of the 'three bodied' psychology. The group become the 'temporary institution' (Pines, 1981, p. 278) - the constellation of the whole, the communicational network and the relational therapeutic factors.

The group 'analytic attitude' (Foulkes, 1975a) is the aspect that is so difficult to 'pick-up' or teach from reading only. This needs refinement, attunement, and an inner state that becomes accessible as a capacity through the group's holding experience. The group as frame generates a multidirectional view of the group as socio-cultural and psychological hotbed for practice and research.

Not only did Pines provide some useful formulations but in my opinion his contribution invited open dialogue, he addressed in his work the following broad intentions:

- accentuate social historical roots,

- theoretical recognition of diverse influences

- internationalisation of group analysis.

Pines' review of historical developments (Pines, 1983; Pines, 1978b; Pines, 2009) is an important contribution to developing settings of training and group work. He identifies the various academic feeders that enriched Foulkes' thinking and opened up the gradual development of a frame that can expand and refocus. Underscoring the multi-directional inquiry that simultaneously contains the foundational ideas and links it to the exploration of unfamiliar of social complexity, the group theorist can maintain an investigative stance. By acknowledging the contradictions, a sensibility for the whole can be fostered.

The foundational formulation extends into a comparative analysis. In discussing Freud's own difficulty in the Viennese society Pines (2002; 1998a) is able to show how these social forces influence thinking, approach, and key theoretical formulations.

Pines (1983) explores the different experiences in Foulkes' life and how these had influenced his thinking. The reader is able to grasp the diversity but also to comprehend the integrative capacity of the group analytic framework. The various transitions are given: as a Jew moving from the embedded German cultural setting during WW1 (Pines, 2002), his professional training and his wide interest in gestalt and social psychology, the work in 
Exeter and the military psychiatry during WW2 (Pines, 2009) and being at the cutting edge of innovative thinking.

Secondly I suggest that Pines introduced difficult and painful historical themes into the professional debate. Again judging from the content and not knowing the response it seems that his entertainment of the Jew-German relationship is one example of using a scholarly attitude in reviewing various positions within historical and contemporary manifestations. In the discussion the reader can start to formulate personal ideas on how such tensions can be transposed to other social settings (Pines, 1998c).

\section{Conceptual clarification and challenge}

Foulkes (1964b) describes the fascinating and powerful construct of 'mirror reactions' which he sees as a very important group specific therapeutic factor. Pines (1982) elaborates how this is not only part of the group experience but also plays a fundamental part in the early infant development. Reflecting on mirroring, we are also given a sense of the tensions held in the primary relation that the infant needs to establish. This construct captures the immediacy of the interretational encounter and broadens the inquiry into primary attachments

This added developmental perspective gives 'mirroring' a layered meaning that contains both the preverbal exchange in primary relations and covers the whole spectrum of more complex constellations that forms part of socialisation. The primary dyadic relationship is enlarged to include the triadic and family constellation. Mirroring therefore becomes more dynamic and multi-dimensional and explains the sudden and uncanny shift in ground and foreground and background that can be experienced in groups.

By adding the metaphorical and mythological dimensions mirroring becomes a construct that can be utilised in various setting. In my opinion it is both a clinical descriptive construct and an investigative apparatus applicable in various group formations and settings. It provides the shared space whereby, through membership and participation, analysis of the intensity and diversity of original states can become accessible.

Pines (1992) further developed the idea of working in the difficult openness of the group space where the conductor needs to find a tolerance for the contradictory states that can exists simultaneously. The presence of emotions that are experience as exclusive but as yet unrecognisable and that needs the group's capacity to elaborate the negative, to be able to use these in a furthering of the shared ability to hold many different feelings at various times. These formulations had been very helpful in situations where the emotive reality felt uncontainable and where the sense of difference had been pre-empted by some violent and negative or non-dialogical mirroring. 
Pines (1978a; 1994; 1990) describes how in his experience with the borderline patients there is an inability to experience mirroring. When he describes some of the relational implications that the small group has to contend with he states how 'pushing the third person out of the dialogue' (1994, p. 135) has to be countered by re-establishing that third position. I think this idea has huge potential for further development. It does not only relay the work and function of containment but also some indication of the collapse of the 'model of three' (Foulkes, 1964a) as a fundamental conceptual structure for group work.

\section{Theoretical condensation and working model formulation}

Pines contributed in two publications (Pines \& Hutchinson, 1993; Pines \& Schlapobersky, 2000) that offers both the novice and seasoned practitioner an outline of the approach and technique. These sources are directed at the wider readership and therefore fit the description of a reference source of group analysis. I found both these publications helpful in teaching and positioning group analysis as part of the spectrum of group therapies. The first offers a grounding exploration of the structural aspects and dynamic administration and a flavour of the thinking pattern, stance and process of analysis. The more recent chapter is very helpful in developing some taxonomy of practices and applications. An academic textbook discourse opens the dialogue with other group work modalities. By defining the basic determinants and clinical settings, trainers and managers in multi-disciplinary treatment staff groups are assisted in making informed decisions based on the assessment of the need and the level of training available.

The International Library of Group Psychotherapy and Process and now the International Library of Group Analysis has over the years played a pivotal role in building our local resources. The collection has provided specific punctuation in the development of the wider understanding of the group and the social domain. Significant links to group work had been offered and as a resource it provides an academic platform to merge various fields of study. Its international character brings an awareness of the confluence and diversity of ideas. Looking at the titles it is evident that group work has progressed using group psychological formulations in breaking new ground. This series has gone a long way in making group analysis part of the academic setting - a wish that Pines (2006) had put forward.

\section{Enlarging the circular exchange}

The Group Analytic Society (London) hosts the frame of continuous development. It will be of value for the internationalisation of group analysis if the various structures in GAS (not only London) and independent societies relay their thinking around present development and support e.g. training, academic curricula, research themes and comparative social descriptive analyses, to assist in forging new links. By sharing these initiatives, the group analytic base for programme development can become part of the broad scope of expanding practice and providing support in pioneering regions. Correspondence shared in the journal and in the Group-Analytic Context has documented work in this regard. As the journal 
becomes more widely read, I suggest a dedicated section conveying these aspects to allow a wider footprint for the group analytic enterprise.

Work from the various subsections of the society has lead to the design of new service delivery systems and changing of the mental process in non-group analytic aligned settings. This offers an interesting challenge: how to maintain the capacity to think and analyse the non-communicational network of organisations reacting to powerful social changes? What is the dynamic of the system that presents the reactive participant and the anxious defensive positions during a transformational epoch? These are socio-contextual, relational and structural mechanisms that engulfs the ratio-relational and activates the diffuse primitive anxieties and defences (Rance, 1998; Rifkind, 1995; Nitsun, 1998).

The Institute of Group Analysis also provides the platform to extend the group analytic frame and developing resources in countries. The block training format (discussed and reviewed in various articles (Behr \& Hearst, 1991)) has provided evidence of the adaptability of the method. This process has enhanced local expertise contributing in ways that had previously been overlooked.

The International Association of Group Therapy and Group Process provides a space for the aligned and non-aligned individuals to become part of the international network. Staying in touch and being informed about separate development can sensitise group practitioners to the different forceful social constellations influencing the discourse and 'chosen domain' of our professional work.

Diversity has become an overused term losing some impact, but the analytic 'social different other' is a primary divider in group encounters. The 'colossal forces' (Pines, $1998 \mathrm{~b}$ ) that it generated brings the primordial and interactional levels of communication and emotive exchange to the fore and is often difficult to 'civilise' into thought. Recent themes (Wilke, 2007; Wolf, 2009) published in the journal and in the series (Jarrar, 2003) (Berke, 2003) has reignited interest in this domain.

\section{The journal as educational forum}

This journal has been crucial in establishing a link to a frame of reference that allowed independent development. The journal has changed from small inner group discussion to an international forum. This makes dialogue difficult at times. It is inevitable but through communication and growing sense of the social embeddedness, it becomes easier to convey complexity within the shared frame of group analysis. Finding the commonalities is often made possible by the broader social theoretical formulations e.g. language and development (Pines, 1992), mental states (Pines, 2006) transcultural group analysis (Brown, 1992; Dalal, 1997) self psychology (Stone, 1992) race relations (Lyndon, 1992; Blackwell, 1994)to name a few. These discussions allows for transfrontier illumination. 
The contributions to the journal have sustained many forays into unfamiliar territory with limited human and supervisory resources. It initiated and activated an 'occupation' and professional concern. It contributed in creating a frame of reference that helped to sustain a dialoguing position during liminal periods and in setting up various working alliances. In reading the journal over many years it often felt like being a member of a free-floating discussion within the scholarly matrix. New thoughts were introduced, some resonating and some alien and provocative bringing an investigative closeness to local relational and contextual tensions. In some instances it helped to define and refine constructs and its applications, in others one could take new avenues. I have realised that thoughts are always connected to the mental processing within the larger group of the readership. Thinking and development takes place in the space between us and is sustained by the awareness that other are present.

I want to reconnect this above experience with two editorial statements:

"It is essentially an expanded circular letter, an international workshop or study group" (Foulkes, 1967, p. 1).

"To extend our boundaries so that we establish and maintain exchanges with our neighbouring and encompassing disciplines of psychoanalysis, social psychology, sociology, anthropology and the humanities. I hope that group analysis can thereby become more acquainted with progress in these fields of knowledge and that interested workers in those fields can increase their knowledge and understanding of the group-analytic approach.” (Pines, 1986, p. 3).

Pines (1986), after giving tribute to the preceding editors, outlines his own vision that had contributed in making the journal successful (Pines, 2000). His specific intent to internationalise the readership and to maintain an inclusive approach to work in the field can be verified. I think both these above aims had been achieved. I think theme-centred issues bring a gravitas and make it the foreground stimulating co-existing themes that runs parallel to this as backdrop. Such tensions stimulate it own volition and adds to credibility.

Another invaluable contribution made through the journal is the publication of the annual Foulkes lecture. I have found the themes stimulating. It will be interesting to follow the thread woven through these themes and formulate some commentary of the group analytic endeavour. In a manner this will become a 'circular review' that illuminates both the conceptual contributions and the social occupation of our times and contexts.

If we take the original matrix of group analysis dating back to 1939-40 (Pines, 2009) we have a very rich heritage of about 70 years to review. Defining different epoch will be useful. Finding links that would enable some understanding of the shifts will enlighten present work. We might find certain transitional phases such as the need to move from the traditional model of training to block training. What conceptual adaptation was required? What were the critical needs addressed? Were other practices affected? 
In concert with Pines' wishes for the journal, I endorse the inclusive and separate development of group analysis internationally. He argues for a stronger academic (Pines, 2006) profile and this should be deliberated across the various international institutional divides. Sharing standards and formats can be one such function. What also needs to be fleshed out is finding ways to redistribute resources - especially in contexts like South Africa where the social needs are overwhelming and the capacity very limited. How can the group analytic currency become social capital invested in the underdeveloped regions? Some valuable experience can be shared by group analysts working in underdeveloped regions.

\section{Transcultural and median group}

The group analytic understanding of social and cultural setting can also be used in setting up transfrontier training and organizational structures. If such initiatives become reality, the cultural and societal forces of the location should be acknowledged and incorporated. Continuous dialogue through workshops and research on the social realities and the unconscious forces (Hopper, 2003) must be sustained. Transforming and adapting the frame will require adjustment. This can happen in an open communication network.. New possibilities in the sphere of technology and innovative can make this work easier. Although this will bring its own complications it leads to new ways of thinking and engagement (Davidson, 1998; Weinberg, 2003).

This observation brought the socio-cultural and historical realities into the foreground and resonated with my awareness around social complexity and social inhibitions.

Understandably South Africa's own colonial history stemming over the full duration of the European settlements since 1652 adds to this on a shared collective level. Academic research gradually became a wider investigation into the seemingly non-clinical fields of race, ethnicity, language, political structures, transcultural settings to name a few. The continuous fear of social collapse and energising enthusiasm about social renewal oscillates strongly and at times violently in a society coping with social transition.

Mirroring has become very helpful in transcultural work where it serves as a reflective surface to a growing awareness of how the 'racial other' directs and diverts the intensity of the quest to meet and belong. Understandably mirroring leads to the acknowledgement of other group phenomena that are evoked as part of the social context. Acknowledging the negative mirroring opened the way to explore those instances in the group when the communication becomes tense and dense and holds more for both the group-as-a-whole and the individuals.

Pines (1982) refers to this but Zinkin (1983) elaborated the destructive potential and discussion the presence of an uncanny atmosphere in the group. Oftentimes in transcultural 
settings the splitting and projections undermines this structural development and the exchange becomes segregated along racial divides.

\section{Conclusion:}

I have reflected on my own journey in becoming acquainted with the theory and practice of group analysis. Initially this was done through academic interest and reading. Gradually I started to gain some understanding of the approach. Group analysis and the wider community provided sustenance during difficult periods. Malcolm had been a central figure in this through his writing, being supportive and inviting; by directing and being appreciative, by providing some foundational ideas but encouraging new thought. I have been encouraged by his enthusiasm and the manner in which he would nudge towards sharing. Being far removed from the inner circle of society and yearly events had contributed to a debilitating sense of isolation. By reviewing his and other's contribution I was also able to gain footing in the developmental work that I am involved with.

I want to echo Pines' sentiment on two accounts. He (2000) suggests that the median and large group will become more important in the future. I want to add that in my experience it offers new working environments that take in the 'total situation of the social unfamiliar'. This work will need a huge effort to record data and formulate evidence based working ideas. Hopefully this will advance our sense of mastering and convening in the wider social sphere.

Pines (2006) would also want to see group analysis becoming an academic discipline. In the academic arena of psychology there is so many competing paradigms that finding space is be difficult. Establishing group work as a core practice in clinical training is a primary task in clinical psychology. Social destructiveness, the breakdown of family structures, and fragmentation of social cohesion are pressing issues requiring an interdisciplinary approach.

Group analysis provides a structure and method that can make an invaluable conceptual contribution. Foulkes in the opening quote referred to group analysis as a 'study method' and I hope that we will develop new innovative ideas to apply this in social studies. This will require refining theoretical formulation and enhancing research approaches. Making a contribution to social change and 'humanising society' (De Maré, 1985) is a huge undertaking.

If this can be achieved group analysis will be acknowledged as a substantial and worthy contributor and partner in academia. Managing the tension between the social and the clinical interest will need a group-wide monitoring. The society and the journal can mediate. This development will be balanced by the way we conduct our business and allow the flow of energy. 


\section{References}

Agazarian, Y. M., \& Peters, R. (1981). The visible and invisible group. Two perspectives on group psychotherapy and group process. International Library of Group Psychotherapy and Group Process. London: Routledge and Kegan Paul.

Behr, H., \& Hearst, L. (1991). 'Block training in group analysis': The debate continues. Group Analysis, 24 (4) 475-477.

Berke, J. H. (2003). The power of projective processes in large groups (Chap. 7). In S. Schneider \& H. Weinberg (eds), The large group re-visited: The herd, primal horde, crowds and masses (pp. 112-122). International Library of Group Analysis 25. London: Jessica Kingsley.

Blackwell, D. (1994). The emergence of racism in group analysis. Group Analysis, 27(2), 197-210.

Brown, D. (1992). Transcultural group analysis II. Use and abuse of cultural differences: Analysis and ethics. Group Analysis, 2 (1) 97-105.

Dalal, F. (1997). A transcultural perspective on psychodynamic psychotherapy: Adressing internal and external realities. Group Analysis, 30 (2) 203-215.

Dalal, F. (1998). Taking the group seriously: Towards a post-Foulkesian group analytic theory. London: Jessica Kingsley.

Davidson, B. (1998). The internet and the large group [Special section continued]. Group Analysis, 31(4), 457-471.

De Maré, P. (1985). Large group perspectives [9th S. H. Foulkes Annual Lecture]. Group Analysis, 18(2), 79-92.

Durkin, H. E. (1964). The group in depth. New York: International Universities Press.

Foulkes, S. H. (1948). Introduction to group-analytic psychotherapy. Studies in the social integration of individuals and groups. London: William Heinemann Medical Books.

Foulkes, S. H. (1964a). Group therapy: Survey, orientation, classification (Chap. 3). In Therapeutic group analysis (pp. 47-53). London: George Allen and Unwin.

Foulkes, S. H. (1964b). Outline and development of group analysis (Chap. 5). In Therapeutic group analysis (pp. 66-82). London: George Allen and Unwin.

Foulkes, S. H. (1964c). Therapeutic group analysis. London: George Allen and Unwin.

Foulkes, S. H. (1967). Editorial. Group Analysis International Panel and Correspondence. London Pergamon. 
Foulkes, S. H. (1975a). Group-analytic psychotherapy: Method and principles. London: Gordon and Breach.

Foulkes, S. H. (1975b). Problems of the large group from a group-analytic point of view (Chap. 1). In L. Kreeger (Ed.), The large group: Dynamics and therapy (pp. 33-56). Itasca, Illinois: F. E. Peacock.

Foulkes, S. H. (1976). Group-analytic dynamics with specific reference to psychoanalytic concepts (Chap. 18). In M. Kissen (Ed.), From group dynamics to group psychoanalysis (pp. 259-270). New York: John Wiley and Sons.

Foulkes, S. H. (1982). Psychodynamic processes in the light of psychoanalysis and group analysis. In S. Scheidlinger (Ed.), Psychoanalytic group dynamics. Basic readings (pp. 147-162). New York: International Universities Press.

Hopper, E. (2003). The social unconscious: Selected papers. In International Library of Group Analysis 22 (M. Pines, Foreword). London: Jessica Kingsley.

Jarrar, L. K. (2003). A consultant's journey into the large group unconscious: Principles and techniques (Chap. 1). In S. Schneider \& H. Weinberg (eds), The large group re-visited: The herd, primal horde, crowds and masses (pp. 29-43). International Library of Group Analysis 25. London: Jessica Kingsley.

Kaplan, H. I., \& Sadock, B. J. (eds). (1983). Comprehensive group psychotherapy (2nd ed). New York: Williams and Wilkins.

Lyndon, P. (1992). The black and white group: A group-analytic contribution to race relations? Group Analysis, 25 (1) 117-120.

Nitsun, M. (1996). The anti-group: Destructive forces in the group and their creative potential. London: Routledge.

Nitsun, M. (1998). The organizational mirror: A group-analytic approach to organizational consultancy, part I - theory [Special section - group analysis and organizations]. Group Analysis, 31(3), 245-267.

Nitzgen, D. (2008). The group analytic movement sixty years on: Revisiting Introduction to Group Analytic Psychotherapy by S.H. Foulkes [The 32nd S.H. Foulkes Annual Lecture]. Group Analysis, 41(4), 325-346.

Parker, I. (1996). Staff-student relationships in universities: Boundary disasters and 'minus k'. Group Analysis, 29 (1) 99-111.

Pines, M., \& Hutchinson, S. (1993). Group analysis (Chap. 2). In A. Alonso \& H. I. Swiller (Eds.), Group therapy in clinical practice (pp. 29-47). Washington DC: American Psychiatric Press.

Pines, M., \& Schlapobersky, J. (2000). Group methods in adult psychiatry (Pt. 6 Treatment methods in psychiatry). In M. G. Gelder, J. J. López-Ibor \& N. 
Andreasen (Eds.), New Oxford textbook of psychiatry (pp. 1442-1462).

Oxford: Oxford University Press.

Pines, M. (1978a). Group analytic psychotherapy of the borderline patient. Group Analysis, 11(2), 115-126.

Pines, M. (1978b). Psycho-analysis and group analysis. Group Analysis, 11(1), 8-20.

Pines, M. (1981). The frame of reference of group psychotherapy. International Journal of Group Psychotherapy, 31(3), 275-285.

Pines, M. (1982). Reflections on mirroring. Group Analysis, 15, Supp 1-26.

Pines, M. (1983). The contribution of S. H. Foulkes to group therapy (Chap. 16). In M. Pines (Ed.), The evolution of group analysis (pp. 265-285). Institute of Group Analysis (London) and the Tavistock Clinic, London. London: Routledge and Kegan Paul.

Pines, M. (1986). Editorial. Group Analysis, 19(1), 3-4.

Pines, M. (1990). Group analytic psychotherapy and the borderline patient (Chap. 2) (B. E. Roth, W. N. Stone, \& H. D. Kibel, eds). In The difficult patient in group: Group psychotherapy with borderline and narcissistic disorders [Monograph 6 AMERICAN GROUP PSYCHOTHERAPY ASSOCIATION MONOGRAPH SERIES] (pp. 31-44). Madison, Connecticut: International Universities Press.

Pines, M. (1992). 'Elaboration of the negative' and other concepts: A tribute to Eduardo Cortesao. Group Analysis, 25(2), 151-167.

Pines, M. (1994). Borderline phenomena in analytic groups (Chap. 6). In V. L. Schermer \& M. Pines (Eds.), Ring of fire: Primitive affects and object relations in group psychotherapy (pp. 128-148). London: Routledge.

Pines, M. (1998a). Change and innovation, decay and renewal in psychotherapy (Chap. 7). In Circular reflections: Selected papers on group analysis and psychoanalysis (Chap. 7, pp. 117-129). London: Jessica Kingsley.

Pines, M. (1998b). Group analysis and healing (Chap. 4). In Circular reflections: Selected papers on group analysis and psychoanalysis (pp. 77-87). London: Jessica Kingsley.

Pines, M. (1998c). Psychoanalysis and group analysis: The Jews and the Germans (Chap. 9). In Circular reflections: Selected papers on group analysis and psychoanalysis (pp. 153-165). London: Jessica Kingsley.

Pines, M. (2000). Shepherding group analysis: Shepherds past, present and future. Group, 24(1), 49-57.

Pines, M. (2002a). The illumination of dreams (Chap. 1) (C. Neri, M. Pines, \& R. Friedman, eds). In Dreams in group psychotherapy: Theory and technique (pp. 25-36). International Library of Group Analysis 18. London: Jessica Kingsley. 
Pines, M. (2002b). The coherency of group analysis [Section: the context of group analysis]. Group Analysis, Vol 35((1)), 13-26.

Pines, M. (2006). How can group analysis become an academic discipline?Group Analysis, 39(2), 273-280.

Pines, M. (2009). The matrix of group analysis: An historical perspective. Group Analysis, 42(1), 5-15.

Rance, C. (1998). The art of conversation: The group-analytic paradigm and organizational consultancy [Special section - group analysis and organizations, Part II]. Group Analysis, 31(4), 519-531.

Rifkind, G. (1995). Containing the containers; the staff consultation group. Group Analysis, 28(2), 209-222.

Shaffer, J. B. P., \& Galinsky, M. D. (1974). Models of group therapy and sensitivity training. New Jersey: Prentice-Hall.

Stone, W. N. (1992). A self psychology perspective of envy in group psychotherapy. Group Analysis, 25 (4) 413-428.

Weinberg, H. (2003). The large group in a virtual environment (Chap. 12). In S. Schneider \& H. Weinberg (eds), The large group re-visited: The herd, primal horde, crowds and masses (pp. 188-200). International Library of Group Analysis 25. London: Jessica Kingsley.

Wilke, G. (2007). 31st S.H. Foulkes annual lecture: Second generation perpetrator symptoms in groups. Group Analysis, 40(4), 429-447.

Wolberg, L. R. (1982). The practice of psychotherapy: 506 questions and answers. New York: Brunner/Mazel.

Wolf, E. (2009). Group helplessness and rage. Group Analysis, 42(2), 177-184.

Yalom, I. D. (1985). The theory and practice of group psychotherapy (3rd ed). New York: Basic Books Inc.

Zinkin, L. (1983). Malignant mirroring. Group Analysis, 16(2) 113-129. 